\title{
ANALISIS PENGARUH KECEPATAN KENDARAAN LISTRIK DAN KECERAHAN LINGKUNGAN TERHADAP HASIL PEMETAAN RUANGAN DARI SENSOR LASER SCANNER
}

\author{
Muh. Abdillah ${ }^{1)}$, Fatkhur Rohman ${ }^{2)}$ \\ ${ }^{1)}$ Mahasiswa Program Studi Teknik Otomotif Elektronik Politeknik Negeri Malang \\ ${ }^{2)}$ Dosen Program Studi Teknik Otomotif Elektronik Politeknik Negeri Malang \\ 1)abdillah.pnup@gmail.com \\ 2) fatkhur_rohman@polinema.ac.id
}

\begin{abstract}
Abstrak
Angka kecelakaan lalu lintas di Indonesia masih tinggi. Menurut Data Badan Pusat Statistik (BPS) jumlah kecelakaan lalu lintas dalam 10 tahun terakhir mengalami fluktuasi, peningkatan paling tinggi terjadi pada 2011, yakni mencapai 108 ribu kasus. Salah satu solusi dari latar belakang tersebut ialah menggunakan sistem autonomus. Tujuan dari penelitian ini adalah untuk mempelajari sistem autonomous menggunakan sensor laser scanner untuk mendeteksi hambatan di sekitar, dan kemudian membuat simulasi pemetaan 2D menggunakan software simulator Rviz dan digabungkan dengan ROS (Robot Operation System). Penelitian ini menjelaskan pengaruh variasi kecepatan mobile robot dan variasi kecerahan lingkungan terhadap hasil pemetaan, dengan asumsi awal tidak terdapat pengaruh terhadap hasil pembacaan sensor. Hasil penelitian mendapati adanya pengaruh kecepatan kendaraan listrik dari kecepatan $0.4 \mathrm{~m} / \mathrm{s}, 1.77 \mathrm{~m} / \mathrm{s}, 2.62 \mathrm{~m} / \mathrm{s}$ dan $3.45 \mathrm{~m} / \mathrm{s}$ terhadap hasil pemetaan. Pengaruh yang diperoleh adalah semakin cepat kendaraan listrik berjalan maka hasil pemetaan semakin tidak akurat. Hal itu disebabkan adanya pngiriman data serial dalam waktu bersamaan. Adapun pengaruh kecerahan lingkungan terhadap hasil pemetaan setelah di uji adalah tidak ada pengaruh. Hal itu disebabkan tingkat kecerahan yang digunakan masih dalam rentang spesifikasi sensor yaitu 10000 lux atau kurang.
\end{abstract}

Kata Kunci: Sensor Laser Scanner, Autonomous, Kendaraan, Kecelakaan Lalu Lintas.

\section{PENDAHULUAN}

Salah satu teknologi yang terbaru saat ini ialah sistem autonomous pada kendaraan. Pada sistem autonomous terdapat berbagai macam sensor-sensor yang sering dipakai sebagai pembacaan rintangan-rintangan ataupun benda-benda di sekeliling sistem tersebut. Beberapa jenis sensor-sensor utama yang sering digunakan ialah sensor ultrasonic, lidar, Global Position System (GPS) dan camera. Jenis sensor-sensor yang digunakan tergantung dari lingkungan dan ukuran robot. (Heiko Hirschmüller, h. 144. 2015). Penelitian mengenai sistem autonomous telah banyak diteliti oleh peneliti-peniliti sebelumnya. Mahasiswa dari Universitas Alcala bernama Angel Llamazares beserta dengan teman sepenelitiannya telah meneliti sistem autonomous yang diterapkan pada kendaraan listrik. Penelitian tersebut, menggunakan Kinect depth camera sebagai sensor dan algoritma Octomap dan Costmap untuk membentuk peta 3D pada simulasi Gazebo/ROS (Robot Operation System). Penelitian berhasil menjalankan kendaraan listrik secara autonomous menggunankan algoritma Octomap dan Costmap. Namun terdapat kelemahan dari penelitian tersebut yaitu menggunakan sensor Kinect camera. Berdasarkan masalah tersebut penulis berinisiatif untuk meneliti sistem autonomous menggunakan sensor laser scanner yang mendeteksi dan membaca halangan lingkungan disekitar, dan kemudian membuat simulasi 2D pemetaan menggunakan Rviz/ROS (Robot Operation System). Sensor laser scanner tentunya memiliki kelebihan dan kelemahan. Sebagaimana yang dikatakan oleh (Heiko Hirschmüller, h. 144. 2015) 
sensor laser scanner memberikan pengukuran yang cukup tepat tanpa postprocessing, namun pengukuran biasanya dibatasi pada satu bidang. Ini berguna untuk lingkungan dalam ruangan dengan dinding lurus, tapi tidak untuk pengaturan luar ruangan yang tidak terstruktur. Pemetaan ruangan akan kurang akurat jika lokalisasi tidak bekerja dengan baik. Seperti yang dikatakan oleh (Angel Llamazares, 2014) tidak mungkin membangun peta jika proses lokalisasi tidak berjalan dengan baik, dan tidak mungkin mendapatkan perangkat dengan presisi tinggi tanpa peta yang akurat. Beberapa kali, teknik SLAM (Simultaneous Localization And Mapping) digunakan untuk mengatasi masalah ini dalam melakukan kedua proses secara bersamaan dan menggunakan berbagai sensor, seperti GPS dan penglihatan, penglihatan dan laser bahkan hanya menggunakan sensor jarak jauh RF. Terdapat berbagai macam algoritma SLAM algorithm untuk melakukan pemetaan. SLAM GMapping merupakan salah satu metode yang dapat digunakan dalam proses pemetaan rungan menggunakan sensor laser scanner. Oleh karena itu pada penelitian ini digunakan algoritma SLAM GMapping.

Sinar laser terbuat dari cahaya yang semuanya terdiri dari panjang gelombang yang sama. Berkas cahaya dalam cahaya biasa mengalir ke arah yang berbeda. Sinar laser bergerak dalam arah yang sama persis. Sinar laser tidak menyebar dan tidak melemah (Zebua, 2011). Laser (singkatan dari bahasa Inggris: Light Amplification by Stimulated Emission of Radiation) merupakan mekanisme suatu alat yang memancarkan radiasi elektromagnetik, biasanya dalam bentuk cahaya yang tidak dapat dilihat maupun dapat lihat dengan mata normal, melalui proses pancaran terstimulasi. Pancaran laser biasanya tunggal, memancarkan foton dalam pancaran koheren (Minarni dan Gita, 2013).

Laser Scanning menggambarkan metode di mana permukaan diambil sampelnya atau dipindai menggunakan tekonolgy laser. Teknonolgi ini menganalisa lingkungan atau objek untuk mengambil data dari bentuknya. Data yang dikumpulkan kemudia dapat digunakan untuk membentuk data digital. Keuntungan dari pemindaian laser adalah kenyataan bahwa ia dapat merekam sejumlah besar titik dengan akurasi tinggi dalam waktu yang relatif singkat. Ini seperti mengambil foto dengan informasi mendalam. Pemindai laser adalah instrumen penglihatan, jadi untuk memastikan cakupan lengkap struktur diperlukan beberapa posisi pengamatan (Leonardo da Vinci, h. 12).

URG-04LX adalah sensor laser untuk pemindaian area. Sumber cahaya sensor adalah laser inframerah Panjang gelombang 785nm dengan keamanan laser kelas 1 . Area pindai adalah $240^{\circ}$ setengah lingkaran dengan radius maksimum $4000 \mathrm{~mm}$ Sudut pitch adalah $0,36^{\circ}$ dan output sensor jarak yang diukur pada setiap titik (683 langkah). Diameter sinar laser kurang dari $20 \mathrm{~mm}$ pada $2000 \mathrm{~mm}$ dengan divergensi maksimum $40 \mathrm{~mm}$ pada $4000 \mathrm{~mm}$. Prinsip pengukuran jarak didasarkan pada perhitungan selisih fasa, karena itu dimungkinkan untuk mendapatkan pengukuran yang stabil dengan pengaruh minimal warna dan pantulan objek (Scanning Laser Range Finder, h2). 


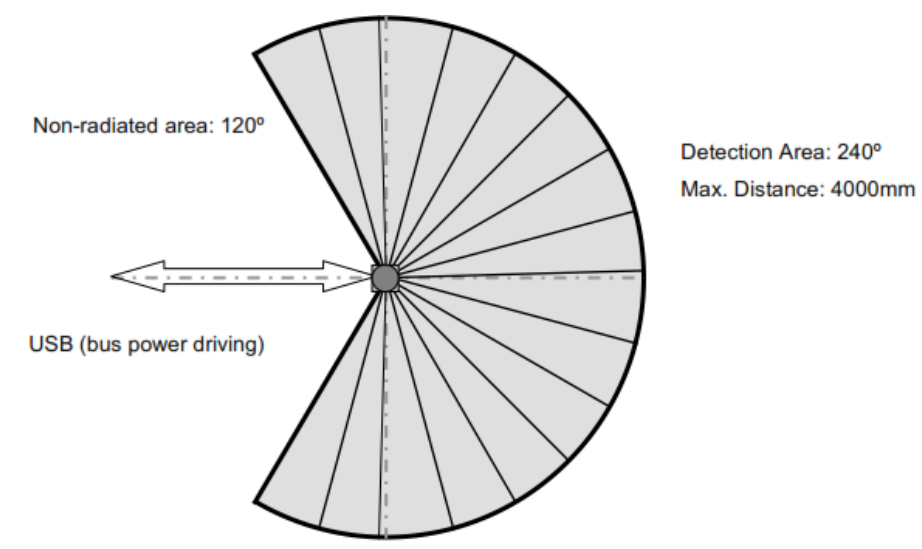

Gambar 1. Area Baca Sensor Hukoyo Laser Scanner

(Mori, hal. 2)

\section{METODOLOGI PENELITIAN}

Pengambilan data dilakukan dengan variasi kecepatan kendaraan listrik dan tingkat kecerahan lingkungan pada sisi timur gedung Sipil 1t. 5. Politeknik Negeri Malang. Data yang diambil berupa jarak dari titik ke titik seperti yang tercantum pada gambar 1. Kemudian jarak tersebut akan di masukkan pada tabel untuk mengetahui perbandingan jarak yang dihasilkan dari masing-masing variabel. Adapun bentuk tabelnya seperti di bawah ini:

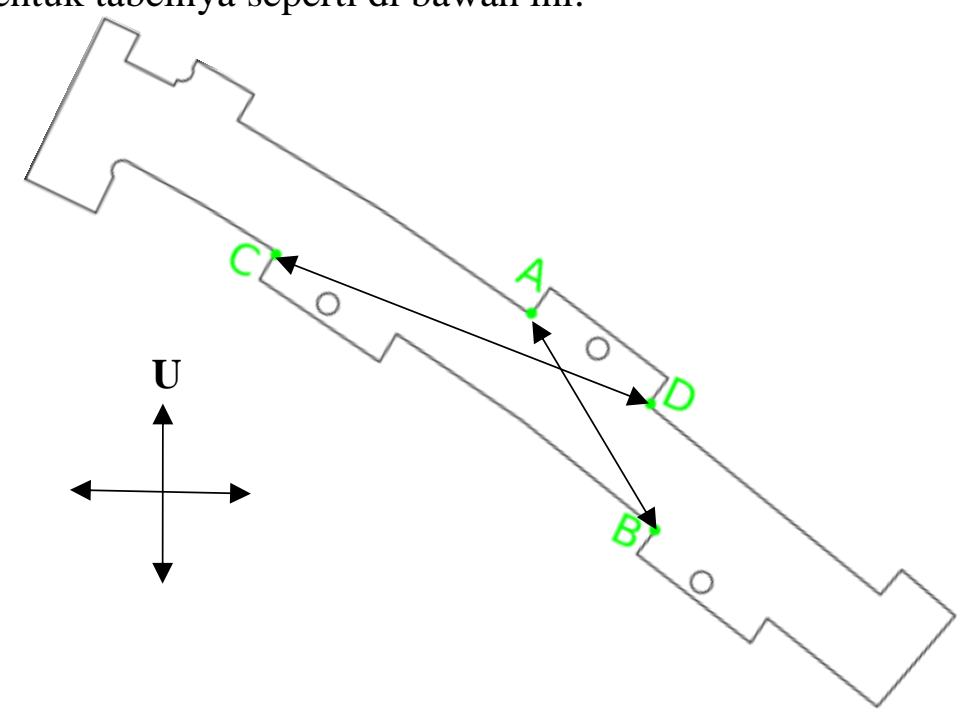

\section{Gambar 2. Sketsa Dena Lantai 5 Sisi Timur Gedung Sipil Politeknik Negeri Malang}

Pengumpulan data penelitian ini diambil dengan variabel kecepatan kendaraan listrik $(0.4 \mathrm{~m} / \mathrm{s}, 1.77 \mathrm{~m} / \mathrm{s}, 2.62 \mathrm{~m} / \mathrm{s}$ dan $3.45 \mathrm{~m} / \mathrm{s})$ dan tingkat kecerahan lingkungan (0 lux, 32 lux, 73 lux dan 104 lux) pada lingkungan indoor yang tetap. Hasil data sensor divisualisasikan ke komputer/PC menggunakan Rviz/ROS (Robot Operation System) berupa pemetaan. Percobaan dilakukan dengan menggunakan kendaraan listrik yang telah terpasang sensor laser scanner kemudian menelusuri ruangan secara autonomous dengan variabel kecepatan dan tingkat kecerahan lingkungan. sesuai dengan pengambilan data yang diinginkan dan mengirimkan data tersebut ke 
komputer/PC berupa visualiasi pemetaan. Dari hasil pemetaan tersebut dilihat tingkat ke akuratan dari hasil pemetaan.

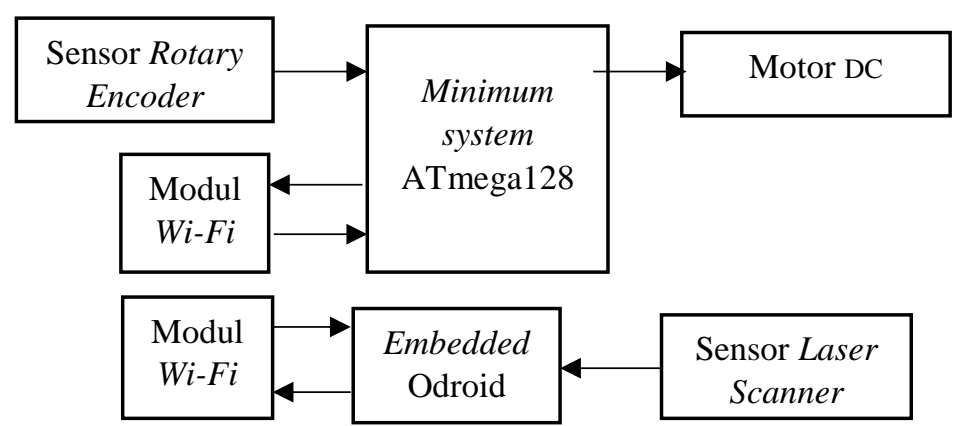

Gambar 3. Diagram komponen Kendaraan listrik

\section{HASIL DAN PEMBAHSASAN}

Pengambilan data dilakukan berdasarkan metode penelitian yang telah tercantumkan di metodolgi dan data diambil di lantai 5 Sisi Timur Gedung Sipil dengan variabel yang telah di tentukan sebelumnya. Adapun data yang telah di peroleh ialah sebagai berikut:

a. Kecepatan
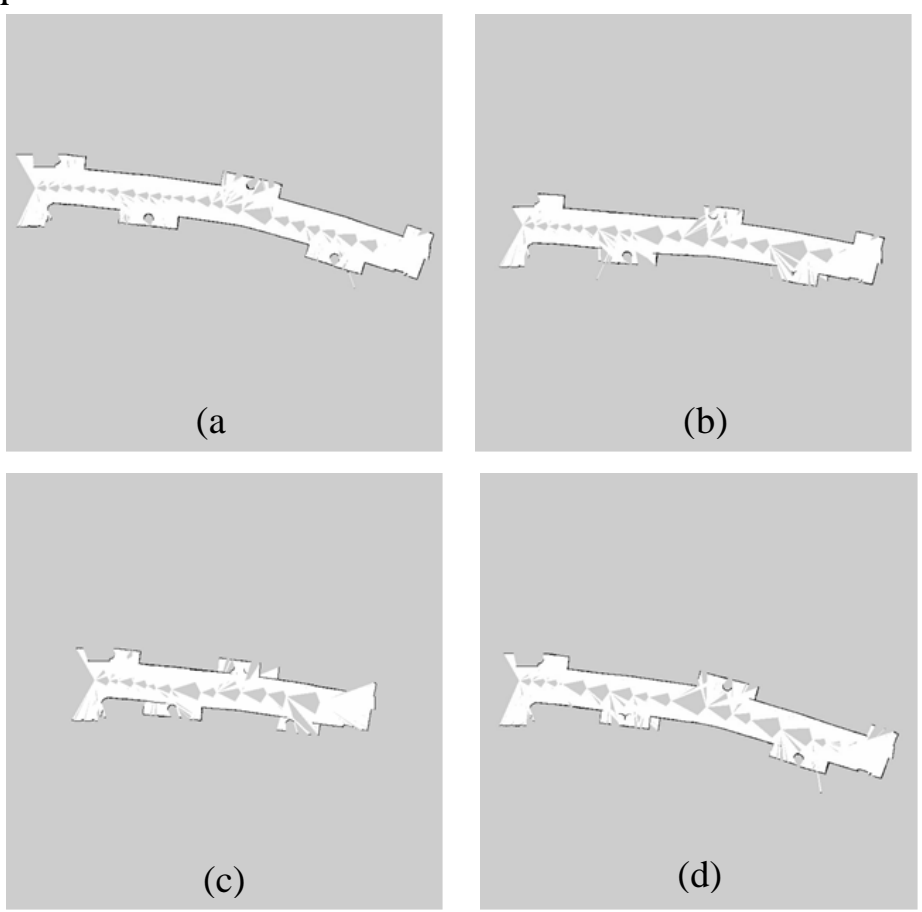

Gambar 4. Hasil Pemetaan Kecepatan (a) $0.31 \mathrm{~m} / \mathrm{s}$, (b) $1.77 \mathrm{~m} / \mathrm{s}$, (c) $2.62 \mathrm{~m} / \mathrm{s}$ dan (d) $3.45 \mathrm{~m} / \mathrm{s}$ 
b. Kecerahan


Gambar 5. Hasil Pemetaan Kecerahan (a) 0 lux, (b) 32 lux, (c) 73 lux dan (d) 104 lux

Simulasi pemetaan divisualisasikan di Rviz/ROS (Robot Operating System). Pada Rviz/ROS (Robot Operating System) diperlukan beberapa sistem pendukung yang harus terpenuhi agar proses pemetaaan dapat berjalan dengan baik.

a. Odometry

Odometry diperlukan untuk membaca jarak/gerakan kendaraan listrik pada Komputer/PC sehingga akan didapatkan jarak dari satu titik ke titik yang lain. Hal ini dikerjakan oleh sensor Rotary Encoder yang terpasang pada roda belakang sebelah kanan dan kiri kendaraan listrik. Sensor Rotary Encoder akan mengeluarkan pulsa ketika berputar. Terdapat 2540 pulsa yang dihasilkan dalam satu kali putaran dan satu putaran roda dapat menempuh jarak $1.6 \mathrm{~m}$. Jadi tiap satu pulsa, kendaraan listrik telah menempuh jarak $0.0006299213 \mathrm{~m}$.

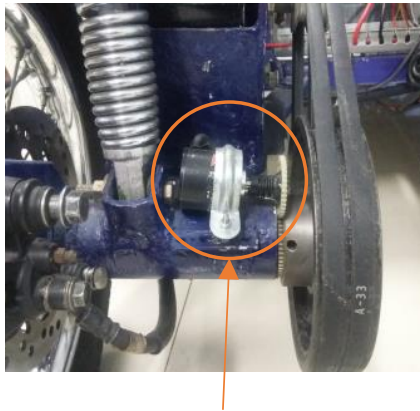

Rotary encoder kiri

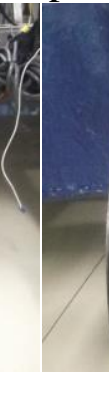

Rotary encoder kanan

\section{Gambar 6. Letak Kedua Sensor Rotary Encoder}




\section{b. Scanning}

Scanning di perlukan untuk mendeteksi halangan yang ada disekitar kendaraan listrik. Proses scanning dilakukan oleh sensor laser scanner. Sensor laser scanner yang digunakan telah didukung oleh ROS (Robot Operation System). Data sensor laser scanner sudah dapat diperoleh dengan menghubungkan langusung ke miniPC yang telah terpasang ROS (Robot Operation System). Oleh karena itu data sensor laser scanner dapat langsung digunakan. Sensor laser scanner terletak pada bagian tengah kendaraan listrik.

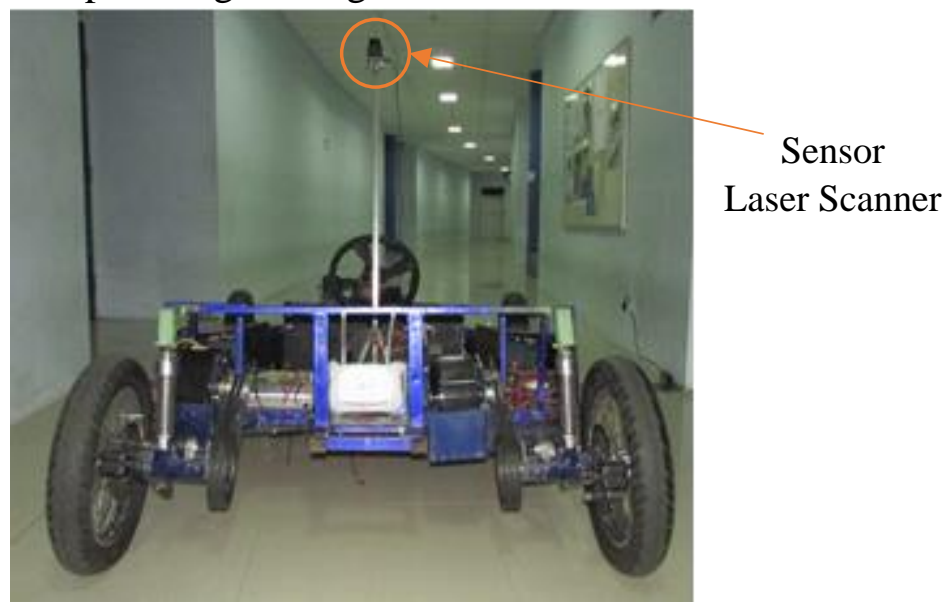

Gambar 7. Letak Sensor Laser Scanner

Setelah mempunyai data odometry dan scanning, maka telah dapat dilakukan proses pembuatan peta pada lingkungan indoor. Pengaruh yang diakibatkan perbedaan kecepatan kendaraan listrik dan kecerahan lingkungan terhadap pembacaan sensor laser dapat dilihat tabel di bagian lampiran. Dari data tersebut didapatkan nilai rata-rata dari tiap-tiap variabel dan tiap-tiap pengambilan data.

1) Pengaruh Kecepatan

Dilihati dari keseluruhan hasil rata-rata data pada tabel 1. terlihat bahwa kecepatan kendaraan listrik sangat berpengaruh terhadap hasil pemetaan. Hal itu disebabkan adanya keterlambatan pengiriman data odomatry ke Rviz. Keterlambatan pengiriaman data tersebut dipengaruhi saat mikrokontroller mingirimkan data odomatry ke komputer/PC melalui komunikasi serial, disaat bersamaan ada perintah dari komputer/PC ke mikrokontroller.

Pada saat pengambilan data, di kecepatan $3.45 \mathrm{~m} / \mathrm{s}$ kendaraan listrik yang ada di Rviz, berjalan sangat cepat dengan gerakan yang tersendat-sendat dan penampilan hasil pemetaan yang terlambat ditampilkan di Komputer/PC. Oleh karena itu, sering terjadi pembacaan peta yang tidak beraturan.

Tabel 1. Data Rata-Rata Pengaruh Kecepatan Terhadap Hasil Pemetaan

\begin{tabular}{|r|l|r|r|}
\hline \multirow{2}{*}{ NO } & \multirow{2}{*}{ KECEPATAN } & \multicolumn{2}{|c|}{ JARAK TITIK (m) } \\
\cline { 3 - 4 } & & A - B & \multicolumn{1}{c|}{ C - D } \\
\hline 1 & $0.4 \mathrm{~m} / \mathrm{s}$ & 8.414 & 12.762 \\
\hline 2 & $1.77 \mathrm{~m} / \mathrm{s}$ & 7.53 & 12.008 \\
\hline 3 & $2.62 \mathrm{~m} / \mathrm{s}$ & 7.296 & 11.59 \\
\hline 4 & $3.45 \mathrm{~m} / \mathrm{s}$ & 6.987 & 10.108 \\
\hline
\end{tabular}




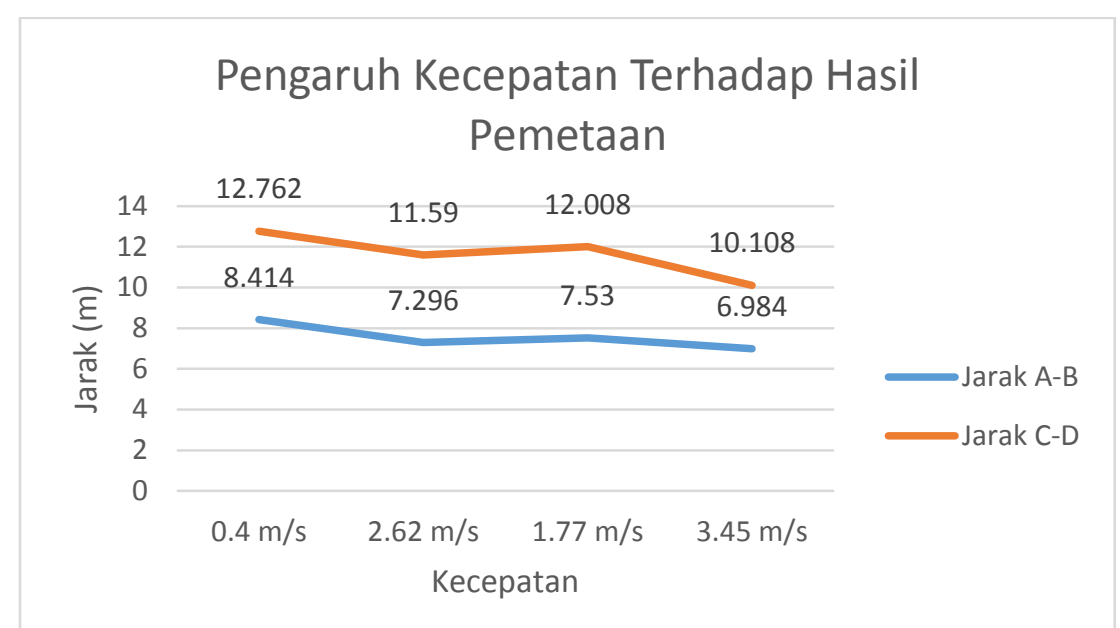

\section{Gambar 8. Grafik Pengaruh Kecepatan Terhadap Hasil Pemetaan}

Untuk mengetahui lebih pasti tentang ada atau tidak adanya pengaruh, maka data variabel kecepatan dikelolah dalam metode One Way Annova. Data tersebut terdapat dilampiran 3 dan 4 . Perlu diperhatikan nilai $P$-value pada tabel tersebut $<0.05$ yang berarti adanya pengaruh terhadap variabel kecepatan.

2) Pengaruh Kecerahan

Pada tabel 2, terlihat pengaruh yang diakibatkan dengan mengubah tingkat kecerahan lingkungan yang ada di sekitar kendaraan listrik tidak bepengaruh signifikan terhadap hasil pemetaan. Hal itu dikarenakan rentang batas pembacaan yang tercantumkan di data sheet sensor laser scanner yang digunakan adalah 0 - 10000 lux, sedangkan pengujian dilakukan pada rentang tingat kecerahan tersebut.

Tabel 2. Data Rata-Rata Pengaruh Kecerahan Terhadap Hasil Pemetaan

\begin{tabular}{|r|l|r|r|}
\hline \multirow{2}{*}{ NO } & \multirow{2}{*}{ KECERAHAN } & \multicolumn{2}{|c|}{ JARAK TITIK (m) } \\
\cline { 3 - 4 } & & A - B & C - D \\
\hline 1 & 0 lux & 7.654 & 11.986 \\
\hline 2 & $32 \operatorname{lux}$ & 7.914 & 11.684 \\
\hline 3 & $73 \operatorname{lux}$ & 7.596 & 11.428 \\
\hline 4 & $104 \operatorname{lux}$ & 8.432 & 12.194 \\
\hline
\end{tabular}




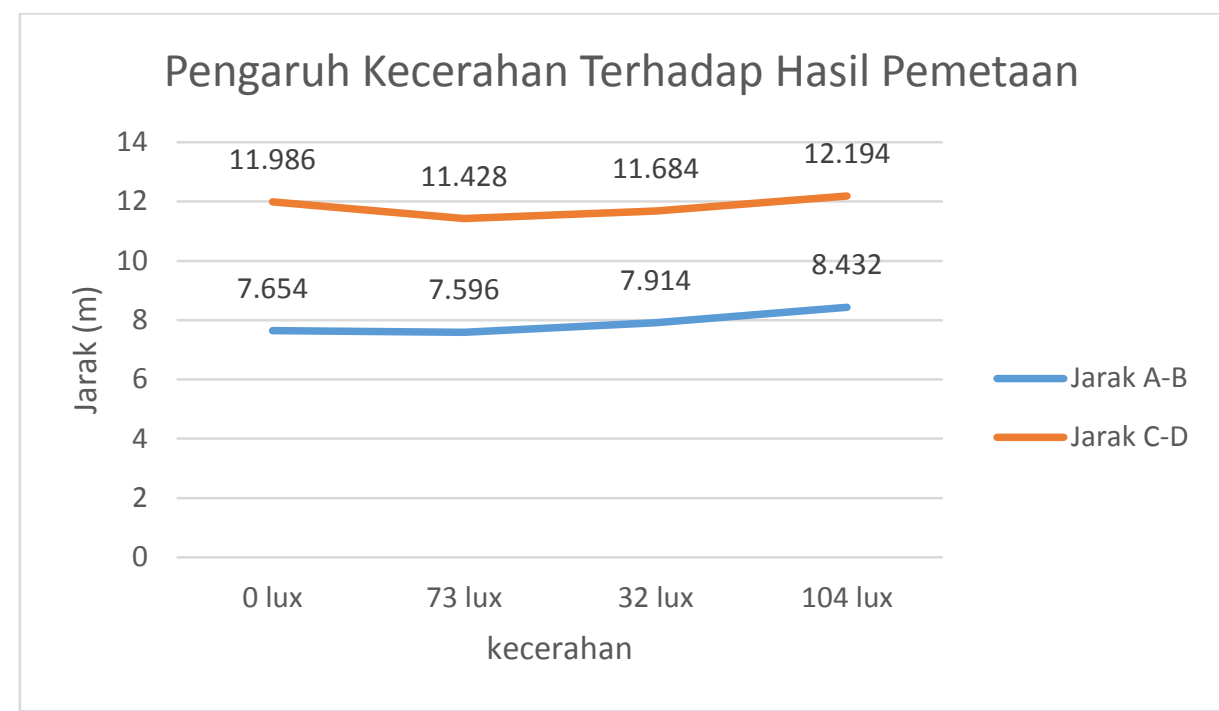

Gambar 9. Grafik Pengaruh Kecerahan Terhadap Hasil Pemetaan

Perlu diperhatikan nilai $P$-value pada kedua tabel 6 dan 5 pada lampiran yaitu $>0.05$ yang berarti tidak adanya pengaruh terhadap variabel kecerahan.

\section{KESIMPULAN}

Pengaruh yang ditimbulkan dari variabel kecepatan berbanding lurus dengan hasil pemetaan, semakin cepat kendaraan listrik berjalan maka peta yang dihasilkan semakin tidak akurat. Berbeda dengan pengaruh dari variabel kecerahan, perubahan yang terjadi pada hasil pemetaan tidaklah signifikan dan bisa dikatakan tidak berpengaruh.

\section{DAFTAR PUSTAKA}

Hirschmüller H, dkk. 2015. Computer Vision for Mobile Robot Navigation. Wichmann, Belin \& Offenbach.

Llamazares A, dkk. 2014. Integrating ABSYTHE Autonomous Navigation System Into ROS. University of Alcala. Madrid (Spain).

Minarni, Saktioto dan Gita lestari. 2013. Pengukuran Panjang Gelombang Cahaya Laser Dioda Mengunakan Kisi Difraksi Refleksi dan Transmisi. Riau: Universitas Riau.

Mori, dkk. 2009. Scanning Laser Range Finder URG-04LX-UG01. Hukoyo Automatic.

Vinci L.D. 2008. Theory and practice on Terrestrial Laser Scanning Training material based on practical applications. Vlaams Leonardo Da Vinci Agentschap v.z.w.

Zebua, Rahmat Syukur. 2011. Jenis Laser Yang Digunakan Sebagai Modalitas Fisioterapi. Medan: Poltekkes YRSU Dr. Rusdi Medan.

LAMPIRAN

Tabel 3. One Way Annova Variabel Kecepatan dengan Jarak Titik A - B

ANOVA

\begin{tabular}{lcccccc}
\hline Source of Variation & SS & $d f$ & $M S$ & $F$ & $P$-value & Fcrit \\
\hline Between Groups & 5.65812 & 3 & 1.88604 & 4.971473 & 0.012616 & 3.238872
\end{tabular}




\begin{tabular}{lrrr} 
Within Groups & 6.06996 & 16 & 0.379373 \\
Total & 11.72808 & 19 & \\
\hline
\end{tabular}

Tabel 4. One Way annova Variabel Kecepatan dengan Jarak Titik C - D

\begin{tabular}{lcrrrrr} 
ANOVA & \multicolumn{1}{c}{ Source of } & & & & & \\
$\quad$ Variation & SS & $d f$ & MS & \multicolumn{1}{c}{ F } & P-value & Fcrit \\
\hline Between Groups & 18.70858 & 3 & 6.236193 & 6.96906 & 0.003263 & 3.238872 \\
Within Groups & 14.31744 & 16 & 0.89484 & & & \\
Total & 33.02602 & 19 & & & & \\
\hline
\end{tabular}

Tabel 5. One Way Annova Variabel Kecerahan dengan Jarak dari Titik A - B ANOVA

\begin{tabular}{lcrcccc}
\hline Source of Variation & \multicolumn{1}{c}{ SS } & $d f$ & MS & F & P-value & F crit \\
\hline Between Groups & 2.18074 & 3 & 0.726913 & 2.028982 & 0.150378 & 3.238872 \\
Within Groups & 5.73224 & 16 & 0.358265 & & & \\
Total & 7.91298 & 19 & & & & \\
\hline
\end{tabular}

Tabel 6. One Way Annova Variabel Kecerahan dengan Jarak dari Titik C - D ANOVA

\begin{tabular}{lrrcccc}
\hline Source of Variation & \multicolumn{1}{c}{ SS } & $d f$ & $M S$ & $F$ & P-value & Fcrit \\
\hline Between Groups & 1.69778 & 3 & 0.565927 & 0.478048 & 0.702022 & 3.238872 \\
Within Groups & 18.94124 & 16 & 1.183828 & & & \\
Total & 20.63902 & 19 & & & & \\
\hline
\end{tabular}


PENA TEKNIK: Jurnal Ilmiah Ilmu-Ilmu Teknik

Volume 3, Nomor 1, Maret 2018: 57 - 66

\section{Halaman ini sengaja dikosongkan}

